\title{
Ampliação da distribuição geográfica de Triatoma deaneorum Galvão, Souza \& Lima 1967, nova denominação para Triatoma deanei (Hemiptera, Reduviidae)
}

\author{
New geographical distribution of Triatoma deaneorum Galvão, Souza \& Lima 1967, \\ new designation for Triatoma deanei (Hemiptera, Reduviidae)
}

\author{
Cleber Galvão', Dayse da Silva Rocha', José Jurberg' e Rodolfo U. Carcavallo
}

\begin{abstract}
Resumo A distribuição geográfica de Triatoma deaneorum Galvão, Souza \& Lima, 1967, nova denominação para Triatoma deanei, é ampliada baseada em um espécime recentemente encontrado no município de Chapada de Guimarães, próximo a Cuiabá, Mato Grosso, Brasil. A nova denominação é baseada no Código Internacional de Nomenclatura Zoológica.
\end{abstract}

Palavras-chaves: Triatominae. Triatoma deanei. Vetores da doença de Chagas

Abstract Authors extend the geographical distribution of Triatoma deaneorum Galvão, Souza \& Lima, 1967, new designation for Triatoma deanei, based on a specimen recently found in Chapada dos Guimarães, near to Cuiabá, Mato Grosso, Brazil. The new designation is based on the International Code of Zoological Nomenclature.

Key-words: Triatominae. Triatoma deanei. Chagas'disease vectors.

Em 1965, Galvão, Souza \& Lima ${ }^{6}$ descreveram Triatoma williami baseado em 16 espécimes capturados no interior de domicílio, na fazenda Antônio Bueno Faria, no município de Piranhas, Estado de Goiás. No mesmo lote de espécimes havia um macho e uma fêmea mortos com caracteres diferentes dos demais, levando os autores a publicarem dois anos mais tarde, uma nova espécie que denominaram de Triatoma deanei ${ }^{7}$. A descrição do holótipo e alótipo dessa espécie foi feita num trabalho mais amplo, onde os autores, fizeram um levantamento das espécies ocorrentes até então no estado de Goiás. Os principais caracteres diferenciais entre as duas espécies estão localizados na cabeça, pronoto, conexivo e trocânteres. Em 1971, Galvão \& Fuentes ${ }^{5}$ voltaram a tratar das duas espécies descrevendo suas ninfas. Lent \& Wygodzinsky ${ }^{9}$ consideraram T. deanei como espécie válida, entretanto, levantaram a hipótese desta ser o resultado de uma possível hibridização entre $T$. infestans e $T$. williami.
Desde sua descrição $T$. deanei não havia mais sido encontrada, em 1999 porém, técnicos da Fundação Nacional de Saúde encontraram um novo espécime fêmea dessa espécie, no interior de domicílio, no município de Chapada dos Guimarães a cerca de 40km de Cuiabá, no Estado de Mato Grosso (Figura 1), por estar seco, não foi examinado para infecção por Trypanosoma cruzi. Este novo espécime, encontrado em uma localidade de outro estado a cerca de $450 \mathrm{~km}$ da localidade tipo, 32 anos após a descrição original, constitui-se então numa ampliação da atual distribuição geográfica desta espécie ${ }^{1}$. Carcavallo et al, em 2000, não puderam incluir $T$. deanei em nenhum complexo específico devido a falta de material para examinar ${ }^{3}$; agora porém, com o estudo desse novo espécime e do holótipo depositado na Coleção Entomológica do Instituto Butantan ${ }^{10}$ foi possível incluí-la no complexo oliveirai face a sua afinidade com as demais espécies desse grupo.

\footnotetext{
1. Laboratório Nacional e Internacional de Referência em Taxonomia de Triatomíneos do Departamento de Entomologia do Instituto Oswaldo Cruz.Rio de Janeiro, RJ.

Com auxílio do CNPq, FAPERJ e convênio FNS/Fiocruz nำ 123/97

Endereço para correspondência: Dr. Cleber Galvão. Depto de Entomologia/FIOCRUZ. Av. Brasil 4365, Manguinhos, 21045-900 Rio de Janeiro, RJ, Brasil. Telefax:55 $212573-4468$.

E-mail galvao@gene.dbbm.fiocruz.br

Recebido em 15/12/2000
} 


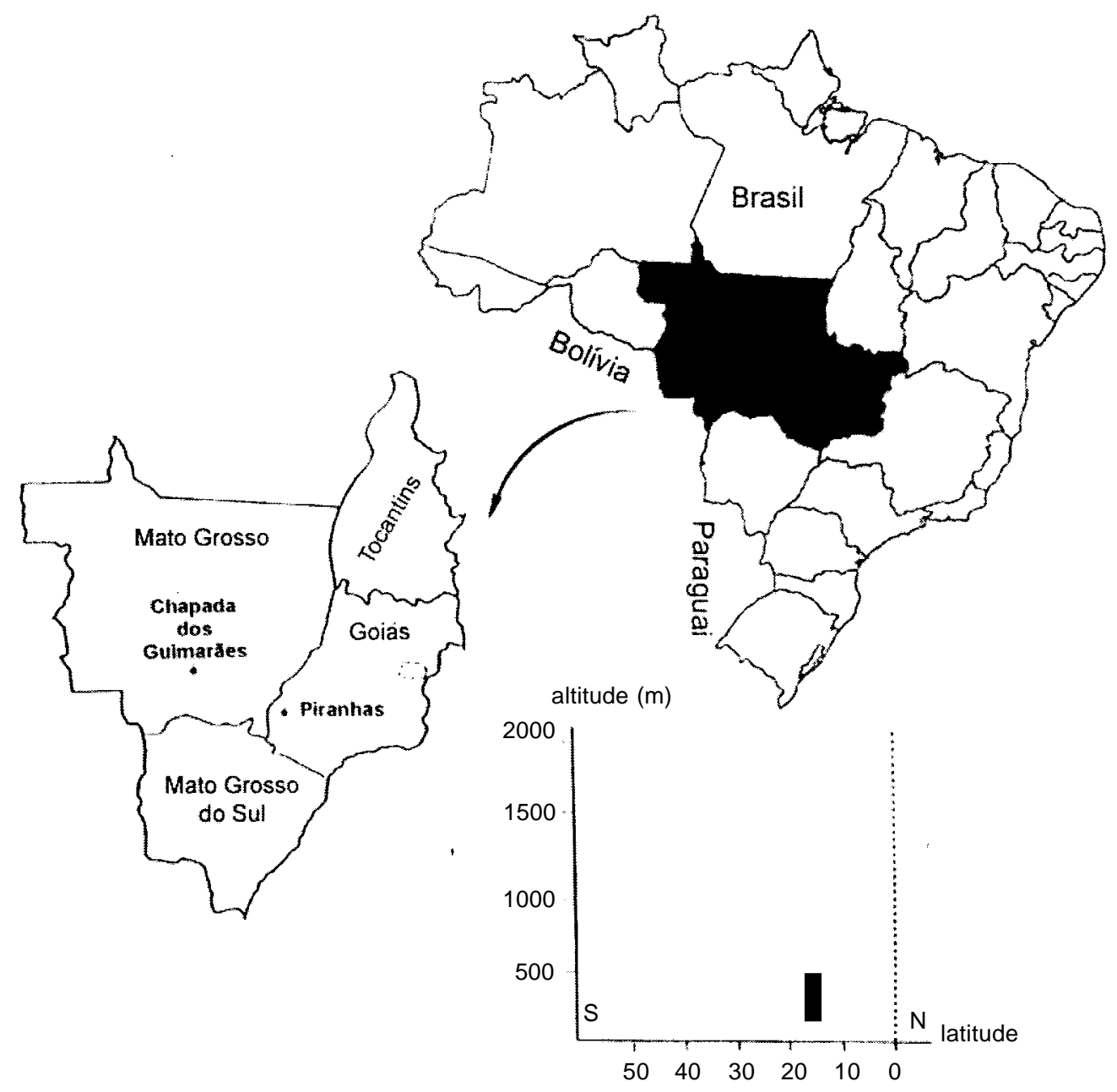

Figura 1- Distribuição geográfica e diagrama de dispersão de Triatoma deaneorum Galvão, Souza \& Lima, 1967.

$\mathrm{Na}$ descrição original a intenção dos autores foi prestar uma "...homenagem aos parasitologistas patrícios: Leônidas de Mello Deane e Maria Paumgarten Deane...", entretanto, ao denominarem a espécie não seguiram o International Code of Zoological Nomenclature $(\mathrm{ICZN})^{8}$, segundo o qual, nomes do grupo da espécie se baseados em nomes pessoais modernos de mais de um homem ou de um ou mais homens e uma ou mais mulheres conjuntamente deve terminar em orum. De acordo com os artigos 32 e 33 do ICZN, a grafia correta, portanto, passa a ser Triatoma deaneorum.

Emendas a grafias originais incorretas em nomes de espécies Triatominae têm sido realizadas ao longo dos anos. Neiva \& Lent ${ }^{11}$ grafaram corretamente Panstrongylus guentheri Berg, 1879 em substituição a grafia original $P$. güntheri, embora a essa época, ainda não existisse uma edição formal do Código. Dipetalogaster maxima (Uhler, 1894) foi proposto por Schofield ${ }^{12}$ em substituição a $D$. maximus já que segundo o Código gaster é feminino (Artigo 34 do ICZN); e Triatoma petrochii Pinto \& Barreto, 1925 foi corrigido por Carcavallo \& Martínez ${ }^{4}$ para T. petrochiae por se tratar de homenagem a uma mulher (Artigo 32 do ICZN). Essas emendas e mudanças estão atualmente aceitas e assim estão citadas no Elenco Bibliográfico dos Triatominae Americanos ${ }^{2}$.

Material examinado: Holótipo macho oㅜ 2.024, Município de Piranhas, Estado de Goiás, Brasil, depositado na Coleção Entomológica do Instituto Butantan, SP. Fêmea no 5.634, Município Chapada dos Guimarães, Estado do Mato Grosso, Brasil, depositado na Coleção Rodolfo Carcavallo, do acervo da Coleção Entomológica do Instituto Oswaldo Cruz, que está sob a responsabilidade e guarda do Laboratório Nacional e Internacional de Referência em Taxonomia de Triatomíneos, Departamento de Entomologia (Figuras 2A e B). 

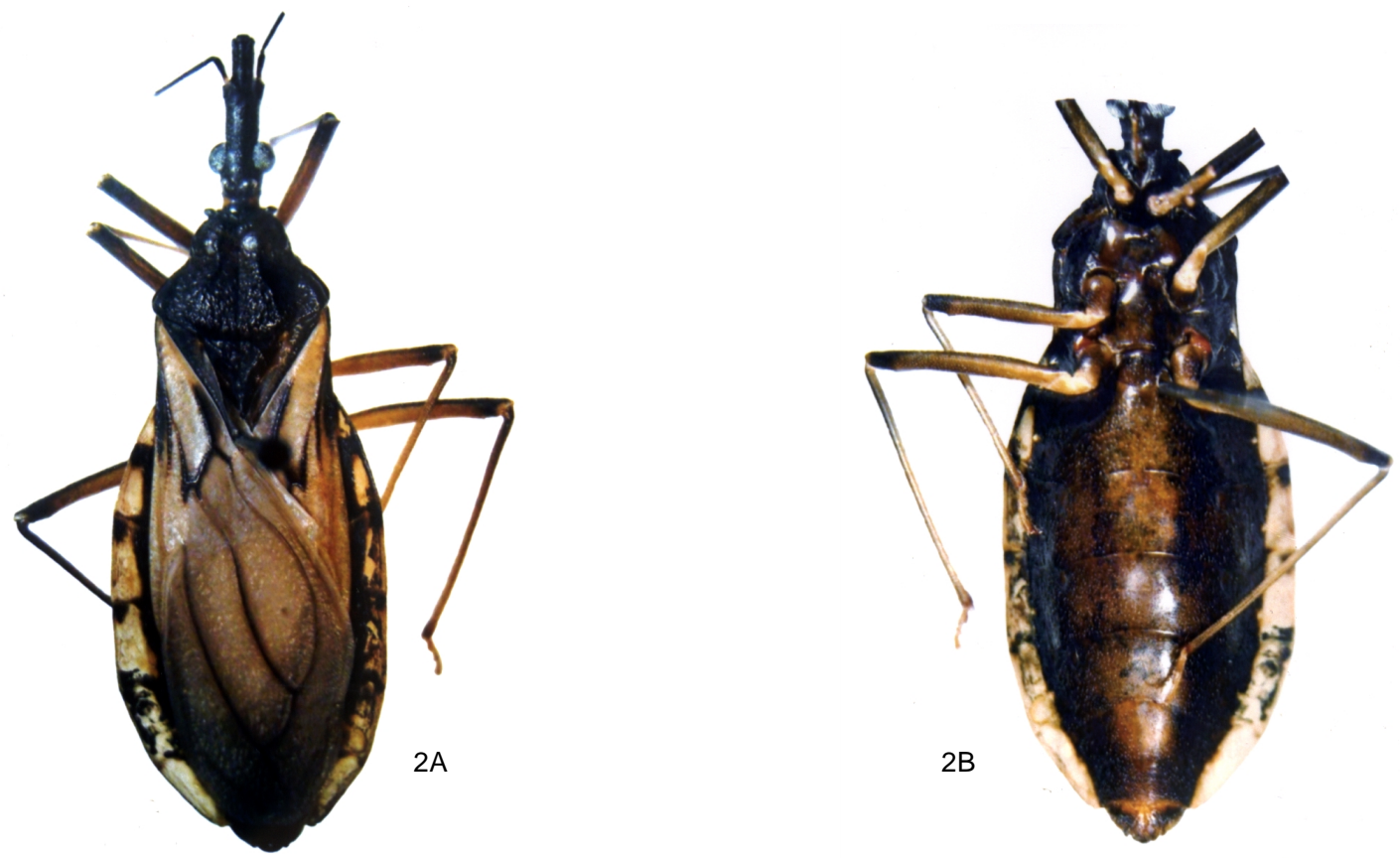

Figura 2 - Triatoma deaneorum Galvão, Souza \& Lima, 1967, fêmea. A: vista dorsal, B: vista ventral.

\section{AGRADECIMENTOS}

A Ana Lúcia Maria Ribeiro da Fundação Nacional de Saúde, MT, pelo envio do espécime estudado. Ao Dr. José Maria Soares Barata da Faculdade de Saúde Pública, SP pelo empréstimo do holótipo e ao Prof. James S Patterson da London School of Hygiene and Tropical Medicine pelas fotografias.

\section{REFERÊNCIAS BIBLIOGRÁFICAS}

1. Carcavallo RU, Curto de Casas SI, Sherlock IA, Galíndez-Girón I, Jurberg J, Galvão C, Mena Segura CA, Noireau F. Geographical distribution and alti-latitudinal dispersion. Distribuição geográfica e dispersão altilatitudinal. In Carcavallo RU, Galíndez-Girón I, Jurberg J, Lent $\mathrm{H}$ (orgs.), Atlas of Chagas' disease vectors in the America. Atlas dos vetores da doença de Chagas na Américas, Volume III, Editora Fiocruz, Rio de Janeiro, p. 747-792, 1999.

2. Carcavallo RU, Galíndez-Girón I, Jurberg J, Lent H, Galvão C, Martínez A. Bibliographic checklist of the American Triatominae. Elenco bibliográfico dos Triatominae Americanos, In: Carcavallo RU, Galíndez-Girón I, Jurberg J, Lent H (orgs.). Atlas of Chagas' disease vectors in the America. Atlas dos vetores da doença de Chagas na Américas, Volume I, Editora Fiocruz, Rio de Janeiro, p. 15-52, 1998.

3. Carcavallo RU, Jurberg J, Lent H, Noireau F, Galvão C. Phylogeny of the Triatominae (Hemiptera: Reduviidae). Proposals for taxonomic arrangements. Entomologia y Vectores 7 (supl I):1-99, 2000.

4. Carcavallo RU, Martínez A. Biologia, ecologia y distribucion geografica de los Triatominos Americanos, In: Carcavallo RU, Rabinovich JE, Tonn RJ (eds) Factores Biologicos y Ecologicos en la Enfermedad de Chagas, Tomo I, Epidemiologia - Vectores, pp. 149-208. № especial de Chagas, Organização Pan Americana de Saúde, Organização Mundial de Saúde, 1985.
5. Galvão AB, Fuentes FB. Descrição das ninfas de Triatoma williami (B. Galvão \& col., 1965) e T. deanei (B. Galvão \& col., 1967) (sic). Revista Goiana de Medicina 17: 141-145, 1971.

6. Galvão AB, Souza AHS, Lima RR. Triatoma williami n. sp. (Hemiptera, Triatominae). Revista brasileira de Malariologia e Doenças Tropicais 17: 363-366, 1965

7. Galvão $A B$, Souza HAS, Lima RR. Espécies de Triatominae ocorrentes em Goiás e descrição de uma nova espécie. Revista Brasileira de Malariologia e Doenças Tropicais 19:397-403, 1967.

8. International Trust for Zoological Nomenclature. International Code of Zoological Nomenclature adopted by the XX General Assembly of the International Union of Biological Sciences, third edition. p. i-xx, 1-338, 1985.

9. Lent $\mathrm{H}$, Wygodzinsky P. Revision of the Triatominae (Hemiptera, Reduviidae) and their significance as vectors of Chagas' disease. Bulletin of American Museum of Natural History 163: 123-520, 1979.

10. Marassá AM, Barata JMS. Nota sobre tipos e espécimes de triatomíneos depositados na Coleção Entomológica do Instituto Butantan, São Paulo (Hemiptera: Reduviidae). Revista da Sociedade Brasileira de Medicina Tropical 33: 227-230, 2000.

11. Neiva A, Lent $H$. Notas e comentários sôbre Triatomídeos. Lista de espécies e sua distribuição geográphica. Revista de Entomologia, Rio de Janeiro 6:153-190, 1936.

12. Schofield CJ. The behaviour of Triatominae (Hemiptera: Reduviidae): a review. Bulletin of Entomological Research 69: 363-379, 1979. 